\title{
Metal content and recovery of MSWI bottom ash in Amsterdam
}

\author{
L. Muchová \& P. C. Rem \\ Delft University of Technology, \\ Faculty of Civil Engineering and Geosciences, The Netherlands
}

\begin{abstract}
Incineration reduces the mass of municipal solid waste (MSW) by $70 \%$ to $80 \%$, and it reduces the volume by $90 \%$. The resulting fractions of the incineration are bottom ash, fly ash and flue gas residue. Bottom ash is by far the largest residue fraction. About 1.1 million tons of bottom ash are produced in the Netherlands and about 20 million tons in Europe, every year. The production of bottom ash is rising because MSW is increasingly incinerated. Bottom ash is land filled in many European countries. However, the material is suitable as a building material from a civil engineering viewpoint, e.g. for embankments and foundations of roads.

Bottom ash contains a considerable amount of non-ferrous and ferrous metals that should be removed for such an application. The recovery of these metals improves the engineering and environmental properties of the ash, and creates a financial benefit. Conventional dry physical methods recover only a small part of the metal value from the ash. This study gives a mass balance for the metal recovery plant of the Amsterdam incinerator (AEB). The results are based on research experiments performed in a new pilot plant for the wet physical separation of bottom ash. The recovery of ferrous and non-ferrous metals is above $70 \%$. The metals that are found in the ash pay for a substantial part of the separation process.
\end{abstract}

Keywords: bottom ash, metal content, physical separation.

\section{Introduction}

Bottom ash from the incineration of household waste is usually treated by magnetic and eddy current separation (for the coarse particle fraction) or it is not treated at all. Therefore, this type of bottom ash represents a large potential for 
the recovery of valuable secondary ferrous and non-ferrous metals. The new pilot plant in Amsterdam can recover both the coarse and the fine ferrous and nonferrous metals by wet physical separation.

The concentration of ferrous and non-ferrous metals in MSWI bottom ash varies for each country and for each incinerator. The raw Amsterdam bottom ash contains $13 \%$ ferrous metals and $2,2 \%$ of non-ferrous metals. The bottom ash from the incinerator of Rotterdam contains $1,2 \%$ of aluminium, $0,2 \%$ of copper, $0,2 \%$ of heavy alloys and $9,9 \%$ of ferrous metals [1]. Chimenos et al. [2] investigated two kinds of bottom ashes from different locations in Spain. The concentration of non-ferrous metals found in the Spanish bottom ash varies between $2 \%$ and $5 \%$ and the concentration of ferrous metals varies between $5 \%$ and $12 \%$.

Physical separation is the most attractive option for the metals recovery from bottom ash. The dry mechanical processing of incineration slag from household waste was tested at the RWTH Aachen for a particle size below $40 \mathrm{~mm}$ [3]. The Aachen process applied eddy current separation, jigging and dense-medium separations. The jig processed the $10-40 \mathrm{~mm}$ fraction and the $0,5-4 \mathrm{~mm}$ fraction. The heavy medium separation was used for the $10-20 \mathrm{~mm}$ fraction and for the 20-40 mm fraction. Each fraction was smelted and the results are shown in Table 1. The process from RWTH shows the concept of multi-step separation of bottom ash. The separation plant in Amsterdam uses dry separation at the first step. The second part of the plant uses wet separation to separate the fraction below $40 \mathrm{~mm}$ [4]. The advantage of wet separation compared to dry separation is a higher recovery.

Table 1: $\quad$ Composition and melting recovery of heavy and light product from RWTH Aachen, (in \% by wt.).

\begin{tabular}{|l|r|r|r|r|}
\hline & $\begin{array}{c}<4 \mathrm{~mm} \\
\text { (light) }\end{array}$ & $\begin{array}{c}4-40 \mathrm{~mm} \\
\text { (light) }\end{array}$ & $\begin{array}{l}<10 \mathrm{~mm} \\
\text { (heavy) }\end{array}$ & $\begin{array}{c}10-40 \mathrm{~mm} \\
\text { (heavy) }\end{array}$ \\
\hline $\mathrm{Al}$ & 95 & 94 & 2,4 & 0,3 \\
Heavy non-ferrous metals & 2,5 & 4 & 70 & 89 \\
Ag & & 8,4 & $1,5-2$ & 88 \\
Melting recovery & 74,4 & 88,4 & 75 & \\
\hline
\end{tabular}

\section{Separation plant in Amsterdam (the Netherlands)}

The former dry physical separation plant in Amsterdam processed approximately 865000 tons of bottom ash in 2005. In the same year, the new wet separation pilot plant was built and optimised to recover more ferrous and non-ferrous metals from the pre-separated bottom ash. Table 2 shows the separated amounts for relevant fractions in 2005 , excluding the metals separated by the new wet separation plant. 


\subsection{Metal content in Amsterdam bottom ash}

The total bottom ash treatment in Amsterdam consists of 3 steps. The first step is the former bottom ash treatment where the bottom ash is screened and shredded to below $40 \mathrm{~mm}$. The main purpose of this step is to remove the ferrous scrap and the very coarse non-ferrous metals. At the second step the fraction between $0-40 \mathrm{~mm}$ is separated by an eddy current separator. The eddy current separator removes the $+15 \mathrm{~mm}$ non-ferrous metals. The residue from the eddy current separator continues to the new wet physical separation pilot plant where the 0 $20 \mathrm{~mm}$ ferrous and non-ferrous metals are removed. The system of three separation steps is shown in Fig.1.

Table 2: $\quad$ Fractions produced in the existing bottom ash dry separation plant.

\begin{tabular}{|l|r|}
\hline & \multicolumn{1}{|c|}{ Ton /Year } \\
\hline Total household waste & 865.000 \\
Bottom ash & 205.000 \\
Ferrous scrap from bottom ash & 15.200 \\
Non-ferrous scrap from bottom ash & 2.100 \\
\hline
\end{tabular}
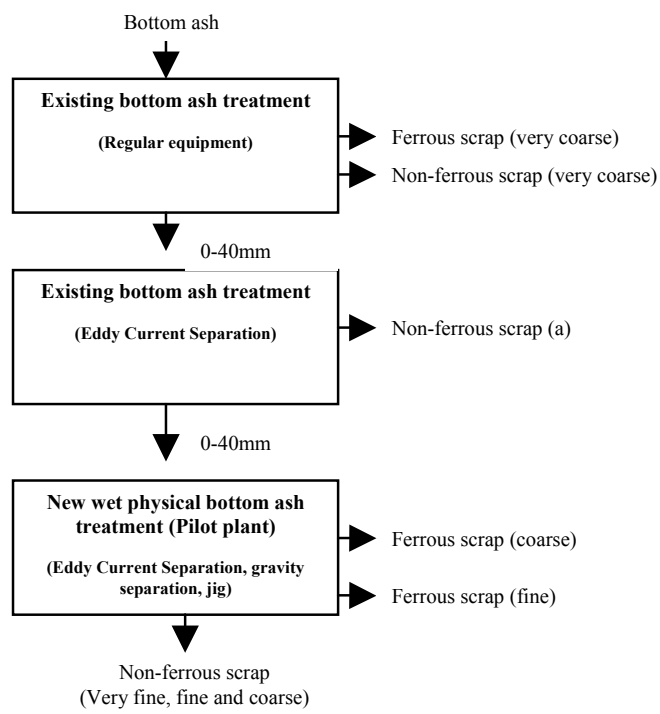

Figure 1: Scheme of the separation system in the AEB Amsterdam.

\subsection{The new wet separation plant for the $0-40 \mathrm{~mm}$ fraction}

The wet pilot plant separates the pre-treated bottom ash based on the size distribution and the density of the particles. The non-ferrous fractions are removed by eddy current separation, density separation [5] and jigging. The 
resulting fractions are the coarse non-ferrous $(6-20 \mathrm{~mm})$, fine non-ferrous $(2-6 \mathrm{~mm})$ and the very fine non-ferrous $(<2 \mathrm{~mm})$ product. The 2-6 $\mathrm{mm}$ aluminium scrap is separated from the heavy non-ferrous by density separation.

The grade and the recovery of magnetic, non-ferrous and aluminium fraction is shown in Table 3.

Table 3: The grade and recovery of the magnetic, non-ferrous and aluminium fractions from the wet separation pilot plant.

\begin{tabular}{|l|r|r|r|r|r|r|}
\hline & \multicolumn{2}{|c|}{ Magnetic fraction* } & \multicolumn{2}{|c|}{ Non-ferrous fraction } & \multicolumn{2}{|c|}{ Aluminium fraction } \\
\cline { 2 - 7 } & $\begin{array}{c}\text { Grade } \\
(\%)\end{array}$ & $\begin{array}{c}\text { Recovery } \\
(\%)\end{array}$ & $\begin{array}{c}\text { Grade } \\
(\%)\end{array}$ & $\begin{array}{c}\text { Recovery } \\
(\%)\end{array}$ & $\begin{array}{c}\text { Grade } \\
(\%)\end{array}$ & $\begin{array}{c}\text { Recovery } \\
(\%)\end{array}$ \\
\hline $6-20 \mathrm{~mm}$ & 62 & 90 & 87 & 77 & n.d. & n.d. \\
$2-6 \mathrm{~mm}$ & n.d. & n.d. & 80 & 81 & 82 & 83 \\
$<2 \mathrm{~mm}$ & 98 & 29 & 29 & 40 & n.r. & n.r. \\
\hline
\end{tabular}

* the magnetic fraction means all magnetic particles removed by magnetic separator.

n.d. - not determined; n.r. - not recovered.

The wet separation pilot plant has a capacity of $50 \mathrm{t} / \mathrm{h}$. The grade and the recovery of the fine and the coarse fraction were measured with the full capacity of the plant. The recovery of the very fine non-ferrous fraction was performed in the laboratory with a magnetic separator that was not optimised. The result from this experiment was added into Table 3. The very fine fraction has to be improved in the future.

\subsection{Experimental result: the grade and recovery of Amsterdam's bottom ash}

The grade and recovery of the combined separation (wet and dry physical separation) is shown in Table 4 . The ferrous concentration of the 6-20 magnetic fractions was estimated as $20 \%$.

Table 4: $\quad$ The grade and recovery of dry separation and wet separation for ferrous scrap, non-ferrous and aluminium fraction.

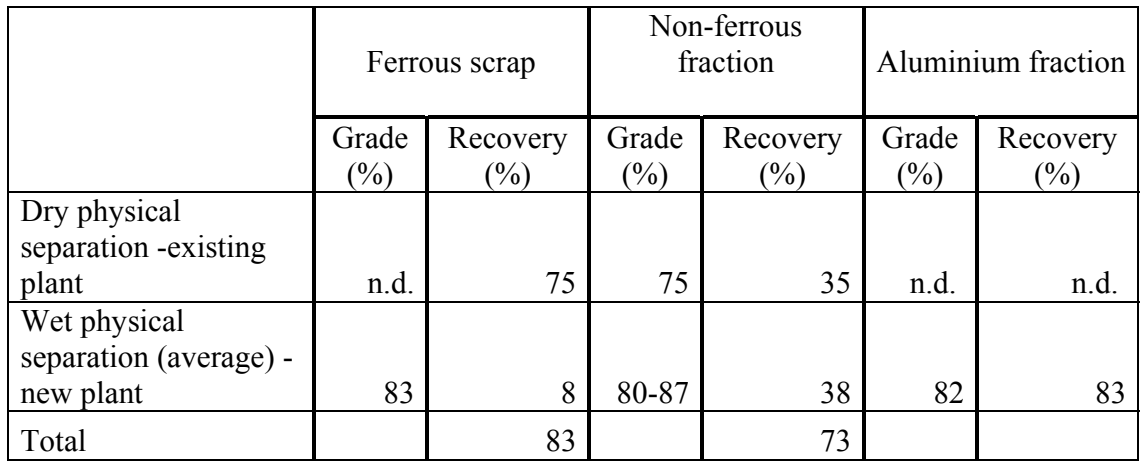

n.d. - not determined. 


\subsection{Precious metals in the Amsterdam's bottom ash}

The content of precious metals in the fine and very fine non-ferrous concentrates removed by the wet physical separation was measured. The non-ferrous metals from the fine and very fine fraction were smelted. The smelts were analysed by drilling holes of $6 \mathrm{~mm}$ diameter through the centre. The drillings were milled and then analysed by XRF. Table 5 shows the average result from the XRF. The results are based on four smelts for each fraction.

Table 5: Precious metal content of fine and very fine fraction analysed by XRF (in ppm).

\begin{tabular}{l|r|r|}
\hline \multicolumn{1}{|c|}{ Element } & Fine fraction & Very fine fraction \\
\hline $\mathrm{Ag}$ & 2700 & n.d. \\
$\mathrm{Au}$ & 82 & 109 \\
$\mathrm{Pt}$ & 14 & n.d. \\
\hline
\end{tabular}

The experimental work with the smelting and analysing by XRF was done by our own procedure with smelting samples of $2 \mathrm{~kg}$ each. An external smelter laboratory was contacted to correlate our result with a bigger sample of $300 \mathrm{~kg}$. The result from the smelter measured a silver concentration of $3700 \mathrm{ppm}$ and a gold concentration of $100 \mathrm{ppm}$. The differences between the results are believed to be due to the heterogeneity of the material.

\section{Conclusion}

The physical separation of bottom ash is successful in recovering metals from the ash at high grade. The second advantage of the separation is minimising the heavy metals in the residue which then is more suitable for the building industry. The physical separation plant in Amsterdam can remove non-ferrous metals with $73 \%$ recovery and $83 \%$ recovery of ferrous scrap. The grades of the fractions satisfy the limits of secondary smelters.

The coarse non-ferrous mixture from the wet physical separation pilot plant has a similar quality to the products of dry processing lines for bottom ash. The prices of the ferrous and non-ferrous metals rapidly increased the last year. The prices offered by sink-floaters for this kind of mixture are about 640 euro/t of non-ferrous at grades better than $75 \%$ metal. Table 6 shows the price of the ferrous, non-ferrous and aluminium scrap removed by the physical separation from the Amsterdam's bottom ash. In Table 6 a value of 640 euro/ton for the non-ferrous fraction was used for the ferrous scrap 140 euro/ton and for aluminium 700 euro/ton. 
Table 6: Prices of the metals removed from the separation plant in Amsterdam in 2005.

\begin{tabular}{|l|r|r|r|}
\hline & $\begin{array}{c}\text { Ferrous scrap } \\
\text { (euro/year) }\end{array}$ & $\begin{array}{c}\text { Non-ferrous scrap } \\
\text { (euro/year) }\end{array}$ & \multicolumn{1}{c|}{$\begin{array}{c}\text { Aluminium } \\
\text { scrap } \\
\text { (euro/year) }\end{array}$} \\
\hline $\begin{array}{l}\text { Dry physical separation- } \\
\text { existing plant }\end{array}$ & 1.596 .000 & 1.102 .500 & n.d. \\
\hline $\begin{array}{l}\text { Wet physical separation } \\
\text { (average) -new pilot } \\
\text { plant* }\end{array}$ & 566.836 & 1.000 .992 & 155.400 \\
\hline Total & 2.162 .836 & 2.103 .492 & 155.400 \\
\hline
\end{tabular}

n.d. - not determined.

* The prices for the metals (separated by pilot plant) are established based of the grade from the experimental result not based on the yearly production. The precious metals were excluded from the calculation.

\section{References}

[1] Waterman, M., Van Houwelingen, J. Economische terugwinning van aluminium uit bodemassen van afvalverbrandingsinstallaties (AVI's). Aluminium 5, 1997.

[2] Chimenos, J.M., Segarra, M., Fernandez, M.A., Espiell, F., Characterization of the bottom ash in municipal solid waste incinerator. Journal of hazardous materials 64, 211-222, 1999.

[3] Schmelzer, G., Wolf, S., Hoberg, H. New wet treatment for components of incineration slag. AT Aufbereitungs Technik, 37, 1996.

[4] Rem, P. C., De Vries, C., Van Kooy, L., Bevilacqua, P., Reuter, M. The Amsterdam pilot on bottom ash, Minerals engineering, 17, 2004.

[5] Van Kooy, L., Mooij, M., Rem, P., Kinetic gravity separation. Physical Separation in Science and Engineering, Vol. 13, No. 1, pp.25-32, 2004. 